Simone D. Hennink, Andrea E. van der Meulen-de Jong, Ron Wolterbeek, A. Stijn L.P. Crobach, Roeland A. Veenendaal, Hans Morreau, and Hans F.A. Vasen, Leiden University Medical Center; Wiet F.S.J. Crobach, W. Rogier ten Hove, and Anne M.C. Witte,

Diaconessenhuis, Leiden; Marco C.J.M. Becx, St Antonius Hospital, Nieuwegein; Michiel van Haastert and Hugo Wolters, Martini Hospital; Jan H. Kleibeuker, University Medical Center Groningen, Groningen; Maarten A.C. Meijssen, Juda Vecht, Wouter H. de Vos tot Nederveen Cappel, and Dik Westerveld, Isala Clinics, Zwolle; Fokko M. Nagengast, Radboud University Medical Center, Nijmegen; Marno C.M Rijk, Amphia Hospital, Breda; Jan M.J. Salemans and Marie-Louise Verhulst, Máxima Medical Center; Arnold Stronkhorst, Catharina Hospital, Eindhoven; Hans A.R.E. Tuynman, Medical Center Alkmaar, Alkmaar; Herman Walinga, Reinier de Graaf Gasthuis, Delft; Olaf K. Weinhardt, Scheper Hospital, Emmen; and Annemieke Cats, National Cancer Institute, Amsterdam, the Netherlands.

Published online ahead of print at www.jco.org on November 2, 2015.

Supported by a grant from ZonMw (Netherlands Organisation for Health Research and Development) project no. 22000075

S.D.H. and A.E.v.d.M.-d.J. contributed equally to this work.

Authors' disclosures of potential conflicts of interest are found in the article online at www.jco.org. Author contributions are found at the end of this article.

Clinical trial information: ISRCTN82767023.

Corresponding author: Hans F.A. Vasen MD, Department of Gastroenterology, Leiden University Medical Center and Netherlands Foundation for the Detection of Hereditary Tumours, Rijnsburgerweg 10, 2333 AA Leiden, the Netherlands; e-mail: hfavasen@stoet.nl. (C) 2015 by American Society of Clinica Oncology

0732-183X/15/3335w-4188w/\$20.00

DOI: 10.1200/JCO 2015.62.2035

\title{
Randomized Comparison of Surveillance Intervals in Familial Colorectal Cancer
}

Simone D. Hennink, Andrea E. van der Meulen-de Jong, Ron Wolterbeek, A. Stijn L.P. Crobach, Marco C.J.M. Becx, Wiet F.S.J. Crobach, Michiel van Haastert, W. Rogier ten Hove, Jan H. Kleibeuker, Maarten A.C. Meijssen, Fokko M. Nagengast, Marno C.M. Rijk, Jan M.J.I. Salemans, Arnold Stronkhorst, Hans A.R.E. Tuynman, Juda Vecht, Marie-Louise Verhulst, Wouter H. de Vos tot Nederveen Cappel, Herman Walinga, Olaf K. Weinhardt, Dik Westerveld, Anne M.C. Witte, Hugo J. Wolters, Annemieke Cats, Roeland A. Veenendaal, Hans Morreau, and Hans F.A. Vasen

Listen to the podcast by Dr Yurgelun at www.jco.org/podcasts

$\begin{array}{llllllll}\text { A } & \text { B } & \text { S } & \text { T } & \text { R } & \text { A } & \text { C } & \text { T }\end{array}$

\section{Purpose}

Colonoscopic surveillance is recommended for individuals with familial colorectal cancer (CRC). However, the appropriate screening interval has not yet been determined. The aim of this randomized trial was to compare a 3-year with a 6-year screening interval.

\section{Patients and Methods}

Individuals between ages 45 and 65 years with one first-degree relative with CRC age $<50$ years or two first-degree relatives with $\mathrm{CRC}$ were selected. Patients with zero to two adenomas at baseline were randomly assigned to one of two groups: group A (colonoscopy at 6 years) or group B (colonoscopy at 3 and 6 years). The primary outcome measure was advanced adenomatous polyps (AAPs). Risk factors studied included sex, age, type of family history, and baseline endoscopic findings.

\section{Results}

A total of 528 patients were randomly assigned (group $A, n=262$; group $B, n=266$ ). Intention-to-treat analysis showed no significant difference in the proportion of patients with AAPs at the first follow-up examination at 6 years in group A $(6.9 \%)$ versus 3 years in group B $(3.5 \%)$. Also, the proportion of patients with AAPs at the final follow-up examination at 6 years in group A $(6.9 \%)$ versus 6 years in group B $(3.4 \%)$ was not significantly different. Only AAPs at baseline was a significant predictor for the presence of AAPs at first follow-up. After correction for the difference in AAPs at baseline, differences between the groups in the rate of AAPs at first follow-up and at the final examination were statistically significant.

\section{Conclusion}

In view of the relatively low rate of AAPs at 6 years and the absence of CRC in group $A$, we consider a 6-year surveillance interval appropriate. A surveillance interval of 3 years might be considered in patients with AAPs and patients with $\geq$ three adenomas.

\section{J Clin Oncol 33:4188-4193. (C) 2015 by American Society of Clinical Oncology}

\section{INTRODUCTION}

Colorectal carcinoma (CRC) is the third most common cancer and fourth leading cause of overall cancer mortality worldwide. ${ }^{1}$ Various population screening programs, including fecal occult blood testing, sigmoidoscopy, and colonoscopy, have been implemented worldwide to detect CRC at an early stage or to prevent the development of CRC by removal of adenomatous polyps. ${ }^{2-8}$ Screening by fecal occult blood testing has been shown to reduce CRC mortality by approximately 15\% and screening by sigmoidoscopy by approximately $50 \% .^{{ }^{9-12}}$

A substantial proportion (10\% to $15 \%)$ of patients with $\mathrm{CRC}$ have a positive family history for
CRC without evidence of an inherited CRC syndrome, such as Lynch syndrome or familial adenomatous polyposis. These individuals have a moderately increased relative risk (RR) of developing CRC, varying from 2 to 6, compared with the general population. Risk depends on the age of onset of CRC in a first-degree relative (FDR) and on the number of family members affected with CRC. An individual with one FDR with CRC diagnosed at age $<50$ years has a reported RR of 3 to 4 , whereas an individual with two FDRs with CRC diagnosed at any age has an RR of developing CRC of 4 to $6 .^{13-16}$

Surveillance of individuals with an elevated risk for familial CRC is attractive for two reasons, first because the reported compliance rate with early 
detection programs is higher than that for average-risk individuals, and second because the yield of surveillance is higher. ${ }^{17-25}$ Although all experts in the field recommend surveillance by colonoscopy, the optimal surveillance interval between colonoscopic examinations has not yet been clearly defined. Current guidelines recommend surveillance at intervals varying from 3 to 5 to 6 years, starting from the age of 45 years. $^{26-28}$

We therefore initiated a multicenter randomized clinical trialthe FACTS (Familial Colorectal Cancer Surveillance) study-in the Netherlands. The objective of this study was to establish the optimal surveillance interval in familial CRC by comparing occurrence of advanced adenomatous polyps (AAPs) in patients under surveillance every 3 years with occurrence in those at an interval of 6 years.

\section{PATIENTS AND METHODS}

\section{Study Design}

This nationwide randomized controlled trial was coordinated by the Netherlands Foundation for the Detection of Hereditary Tumors at Leiden
University Medical Center in Leiden. Colonoscopies were performed by trained gastroenterologists. On the basis of the results of the baseline colonoscopy, patients were assigned to different study groups (groups A and B). Patients who had $\geq$ three adenomatous polyps at baseline were excluded and scheduled for a follow-up colonoscopy at 3 years. Patients with zero, one, or two adenomatous polyps at baseline were randomly assigned to one of two groups: Group A underwent colonoscopy at 6 years, whereas group B underwent follow-up colonoscopies at 3 and 6 years (Fig 1). The study protocol was approved by the medical ethics committee at Leiden University Medical Center and by the local medical ethics committees at collaborating hospitals. The study complies with the CONSORT checklist published in 2010.

\section{Participants}

As described previously, ${ }^{29}$ all gastroenterologists and general practitioners (GPs) in the Netherlands were informed about the study. Individuals interested in participating provided both written informed consent and completed a questionnaire regarding their personal medical and family histories. The family history was verified with medical and pathology reports. In suspected cases of hereditary CRC syndrome (patients with CRC age $<50$ years), tumors were analyzed for microsatellite instability (MSI), and patients with MSI-high tumors were referred to clinical genetic centers.

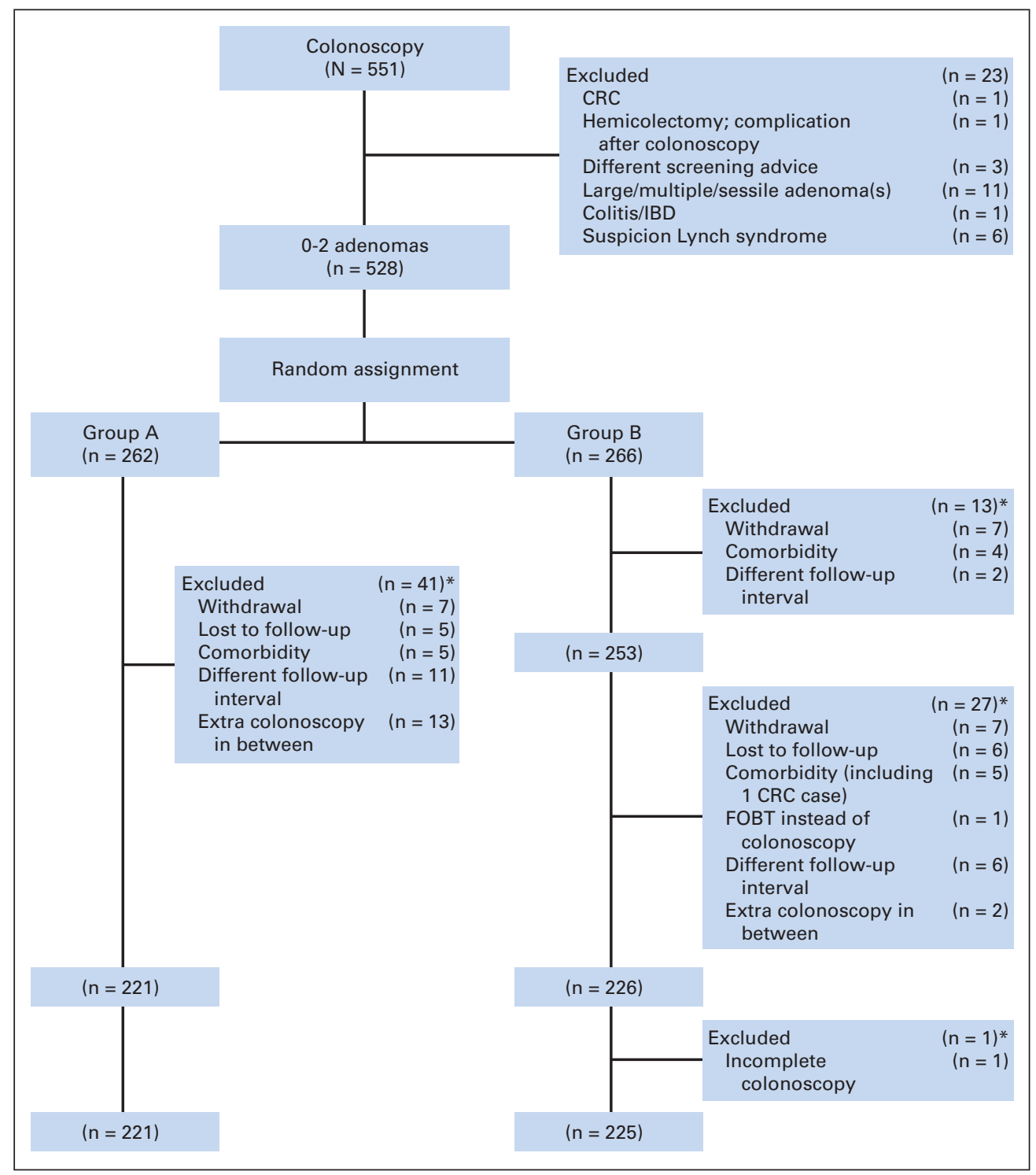

Fig 1. CONSORT diagram/flowchart. CRC, colorectal cancer; FOBT, fecal occult blood test; IBD, inflammatory bowel disease. (*) Included in intention-to-treat analysis. 
The inclusion period was 2002 to 2007. Individuals were considered eligible for inclusion if they met the following criteria: age between 45 and 65 years with a positive family history of CRC (ie, one FDR diagnosed with CRC at age $<50$ years or two FDRs diagnosed with $\mathrm{CRC}$ at any age). Ineligibility was determined on the basis of additional FDRs or second-degree relatives with CRC, a personal history of inflammatory bowel disease, previous colorectal surgery, an FDR with CRC with known MSI, or strong suspicion of Lynch syndrome (eg, combination of CRC and endometrial cancer).

The collaborating centers selected participants using the abovementioned criteria. The informed consent of individuals meeting these criteria was sent to the coordinating center. At the coordinating center, the selected patients from participating centers were alternately allocated, determined by the inclusion order, to the two groups (A and B) by the study coordinator. Participants were not stratified according to sex or participating center. After completion of the randomization process, participants and their gastroenterologists and GPs were informed about their allocated group and the time of the next scheduled colonoscopy.

\section{Colonoscopic Surveillance and Pathologic Review}

The outcomes of all colonoscopic examinations were collected at the study center. Information was also gathered on the completeness of colonoscopic examination (visualization of appendiceal opening, cecal valve, and/or insertion of terminal ileum). If the colon was severely contaminated, the examination was repeated.

All pathology reports and adenomas were reviewed by one pathologist in Leiden (H.M.). The primary outcome measure was the presence of an adenoma with advanced pathology (AAP), defined as an adenoma with either high-grade dysplasia, tubulovillous or villous architecture, or a size $\geq 1 \mathrm{~cm}$ in diameter. The secondary outcome measure was the presence of adenomas.

\section{Statistical Analysis}

Sample-size calculations were based on the detection of a difference in percentage of patients with AAPs at 3 years of $3.75 \%$ (in group B) and at 6 years of $10 \%$ (in group A), with a power of $80 \%$ and one-sided level of significance of .05 , requiring 468 and 624 patients, respectively, taking into account a predicted $25 \%$ dropout rate resulting from noncompliance (10\%), incidence of multiple polyps (10\%), and sessile polyps $>3 \mathrm{~cm}$ and malignant adenomas (5\%). During recruitment, we found that the dropout rate was much lower than expected (approximately $10 \%$ instead of $25 \%$ ), and as a consequence, fewer patients were required.

According to the principles of intention-to-treat analysis, patients with follow-up examinations that deviated from the scheduled protocol were analyzed in their original randomization group. Logistic regression analysis calculating odds ratios (ORs) was used for comparison of the proportions of patients developing AAPs (primary outcome) and adenomas (secondary outcome) at the first follow-up (6 years in group A compared with 3 years in group B) and final follow-up examinations (6 years in group A compared with 6 years in group B).

Logistic regression models were also used for the risk factor analysis. The following risk factors were analyzed as predictors for developing AAPs by the first follow-up examination (intention-to-treat analysis): sex, age at enrollment, age group ( $\leq$ and $>55$ years), type of family history, and findings at baseline (presence of adenoma, adenoma in proximal colon, and AAPs). All reported $P$ values are two sided, and values $<.05$ were considered significant. All analyses were performed using SPSS software (version 22; SPSS, Chicago, IL).

\section{RESULTS}

\section{Baseline Findings and Features of Study Groups}

A total of 551 patients accepted the invitation to participate in the FACTS study. Family history was confirmed by medical records in 99\% of all patient cases, and family history for CRC could be confirmed by pathology reports in $47 \%$ of patient cases. All participants

\begin{tabular}{|c|c|c|}
\hline \multirow[b]{2}{*}{ Characteristic } & \multicolumn{2}{|c|}{ No. of Patients (\%) } \\
\hline & $\begin{array}{l}\text { Group A } \\
(n=262)^{*}\end{array}$ & $\begin{array}{c}\text { Group B } \\
(n=266) \dagger\end{array}$ \\
\hline \multicolumn{3}{|l|}{ Age, years } \\
\hline Median & 53.0 & 53.5 \\
\hline IOR & $49-57$ & $49-58$ \\
\hline \multicolumn{3}{|l|}{ Age group, years } \\
\hline$\leq 55$ & $174(66)$ & $157(59)$ \\
\hline$>55$ & $88(34)$ & $109(41)$ \\
\hline \multicolumn{3}{|l|}{ Sex } \\
\hline Male & $125(48)$ & 102 (38) \\
\hline Female & $137(52)$ & $164(62)$ \\
\hline \multicolumn{3}{|l|}{ Family history of CRC } \\
\hline One FDR age $<50$ years & $129(49)$ & $130(49)$ \\
\hline Two FDRs at any age & $133(51)$ & $136(51)$ \\
\hline Two age $<70$ years & $50(19)$ & $52(20)$ \\
\hline One age $<70$ and one age $>70$ years & $65(25)$ & $73(27)$ \\
\hline Two age $>70$ years & $18(7)$ & $11(4)$ \\
\hline \multicolumn{3}{|l|}{ Adenomas } \\
\hline No & $216(82)$ & 220 (83) \\
\hline Yes & $46(18)$ & $46(17)$ \\
\hline \multicolumn{3}{|l|}{ Proximal adenomas } \\
\hline No & $246(94)$ & $249(94)$ \\
\hline Yes & $15(6)$ & $17(6)$ \\
\hline Unknown & $1(0.3)$ & \\
\hline \multicolumn{3}{|l|}{ AAPs } \\
\hline No & $257(98.1)$ & $251(94.4)$ \\
\hline Yes & $5(1.9)$ & $15(5.6)$ \\
\hline \multicolumn{3}{|c|}{$\begin{array}{l}\text { Abbreviations: AAP, advanced adenomatous polyp; CRC, colorectal cancer; } \\
\text { FDR, first-degree relative; IQR, interquartile range. } \\
\text { "One examination (at } 6 \text { years). } \\
\text { †Two examinations (at } 3 \text { and } 6 \text { years). }\end{array}$} \\
\hline
\end{tabular}

underwent a baseline colonoscopy in the period from 2002 to 2007. The cecum was visualized in $93 \%$.

For reasons shown in Figure 1 (upper row), 23 patients were excluded from the study. Eight of the 23 patients had $\geq$ three adenomatous polyps. Follow-up colonoscopy at 3 years was thus advised according to national guidelines. Of the remaining 528 patients with zero, one, or two adenomatous polyps at baseline, 262 were randomly assigned to group A for colonoscopy at 6 years and 266 to group B for follow-up colonoscopy at both 3 and 6 years (Table 1). Endoscopical findings at baseline are listed in Table 1. Patients in group B were found to have more AAPs at baseline than those in group A.

\section{First Follow-Up Examination}

A total of 245 patients (94\%) in group A returned for a follow-up colonoscopy. The cecal intubation rate was $95 \%$. Twenty-four $(10 \%)$ of the 245 patients had either a follow-up interval that deviated by $>1$ year from the planned scheduled colonoscopy interval or an additional colonoscopic examination before the scheduled examination.

In group B, 255 patients (96\%) returned for the first follow-up colonoscopy. The cecal intubation rate was also 95\%. Two $(0.8 \%)$ of the 255 patients did not comply with the originally defined follow-up schedule.

The outcomes of colonoscopy at 6 years in group A and 3 years in group B were compared in the intention-to-treat analysis. The proportion of patients with adenomas was $26 \%$ after 6 years compared 


\begin{tabular}{|c|c|c|c|}
\hline \multirow[b]{2}{*}{ Finding } & \multicolumn{2}{|c|}{ First Follow-Up Examination } & \multirow{2}{*}{$\begin{array}{c}\text { Second Follow-Up } \\
\text { Examination } \\
\text { Group B } \\
(n=234)^{*}\end{array}$} \\
\hline & $\begin{array}{l}\text { Group A } \\
(n=245)^{*}\end{array}$ & $\begin{array}{c}\text { Group B } \\
(n=255) \dagger\end{array}$ & \\
\hline Adenomas, No. (\%) & $63(26)$ & $32(13)$ & $46(20)$ \\
\hline \multicolumn{4}{|l|}{ Crude OR (95\% Cl) } \\
\hline 6-year A v 3-year B & \multicolumn{3}{|c|}{2.4 (1.5 to 3.9$)$} \\
\hline 6-year A $\vee 6$-year B & \multicolumn{3}{|c|}{1.4 (0.92 to 2.2 ) } \\
\hline AAPs, No. (\%) & $17(6.9)$ & $9(3.5)$ & $8(3.4)$ \\
\hline \multicolumn{4}{|l|}{ Crude OR $(95 \% \mathrm{Cl})$} \\
\hline 6-year A $\vee$ 3-year B & \multicolumn{3}{|c|}{2.0 (0.89 to 4.7$)$} \\
\hline 6-year A $v$ 6-year B & \multicolumn{3}{|c|}{2.1 (0.89 to 5.0$)$} \\
\hline \multicolumn{4}{|l|}{ Adjusted OR (95\% Cl) } \\
\hline 6-year A v 3-year B & \multicolumn{3}{|c|}{2.44 (1.03 to 5.78$)$} \\
\hline 6-year A $v$ 6-year B & \multicolumn{3}{|c|}{2.61 (1.06 to 6.45$)$} \\
\hline \multicolumn{4}{|c|}{$\begin{array}{l}\text { Abbreviations: AAP, advanced adenomatous polyp; OR, odds ratio. } \\
\text { "At } 6 \text { years. } \\
\text { †At } 3 \text { years. }\end{array}$} \\
\hline
\end{tabular}

with $13 \%$ after 3 years (crude OR, 2.4; 95\% CI, 1.5 to $3.9 ; P<.001$; Table 2). The proportion of patients with AAPs after 6 years was $6.9 \%$ compared with 3.5\% after 3 years (crude OR, 2.0; 95\% CI, 0.89 to 4.7; $P=.09)$. There was one patient case of incident in CRC group B after 3 years, a poorly differentiated tumor in the splenic flexure (stage pT3N0). For the purposes of analysis, this patient case was included with the AAPs.

AAPs at baseline were found in five (1.9\%) of 262 patients in group A and in 15 (5.6\%) of 266 patients in group B. We corrected for this finding in a bivariable logistic regression analysis with study group and AAPs (as dichotomous variable) in the model. After correction for the differences in presence of AAPs at baseline between the two groups, the difference in the presence of AAPs at first follow-up was statistically significant (adjusted OR, 2.44; 95\% CI, 1.03 to 5.78; $P=.044)$.

\section{Second Follow-Up Examination}

A total of 235 (88\%) of the original 266 patients in the group requiring two examinations (group B) returned for their second follow-up colonoscopy. The cecal intubation rate was $96 \%$.

Ten (4\%) of 235 patients had different follow-up intervals or incomplete or additional unplanned colonoscopies. At the second examination of group B at 6 years, a lower proportion of patients had adenomas and AAPs compared with the single-examination group (group A) at 6 years. However, the differences were not significant in the intention-to-treat analysis (Table 2). After correction for the difference in presence of AAPs at baseline between the two groups, the difference in the presence of AAPs at the final examination was statistically significant (adjusted OR, 2.61; 95\% CI, 1.06 to 6.45; $P=.038$; Table 2).

\section{Risk Factors}

Sex, age, type of family history, and findings at baseline colonoscopy were analyzed as individual risk factors for the development of AAPs at the first follow-up examination in group A at 6 years and in group B at 3 years. Patients with a different follow-up interval or with additional unplanned colonoscopies were included in the intentionto-treat analysis. Only AAPs were identified as a predictor for the

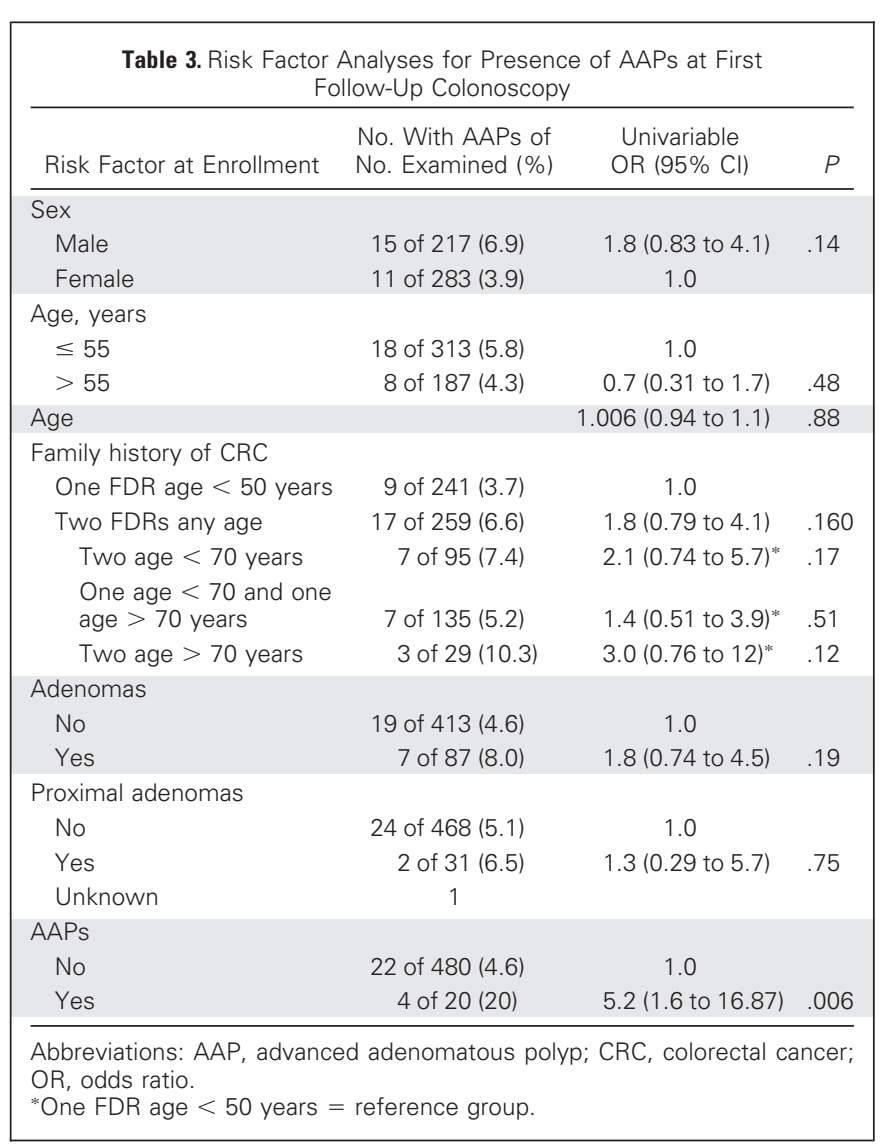

development of AAPs by first follow-up (OR, 5.21; 95\% CI, 1.61 to $16.87 ; P=.006$; Table 3 ).

\section{DISCUSSION}

Hereditary factors play a role in a substantial proportion of patient cases of CRC. Although 3\% to 5\% of all patient cases of CRC result from hereditary cancer syndromes, such as Lynch syndrome and polyposis syndromes, $5 \%$ to $10 \%$ of all patient cases of CRC are caused by a combination of hereditary and environmental factors; these are collectively referred to as familial CRC. The lifetime risk of developing CRC for individuals with hereditary CRC syndromes varies from approximately 50\% in Lynch syndrome to 90\% in familial adenomatous polyposis. In familial CRC, the lifetime risk is approximately $10 \%$ to $20 \%$, depending on the age of onset of CRC in the FDR and on the number of affected FDRs. ${ }^{13,15,16}$

The frequency of a significant family history of CRC (ie, one FDR with early-onset CRC or two FDRs with CRC) in the general population age between 45 and 70 years is approximately $2 \% .^{30}$ The expected number of individuals with familial CRC in the United States is 2.7 million.

British investigators have shown that colonoscopic surveillance in high-risk families leads to a reduction in the incidence of CRC and CRC-related mortality by $>80 \% .{ }^{31}$ However, the study, which is the only available investigation in this field, did not include a control group, and the $>80 \%$ reduction was calculated by comparing the observed incidence of CRC and mortality in the 
high-risk cohort under surveillance with those expected in the absence of surveillance.

Although colonoscopic surveillance in familial CRC is currently recommended by all experts, the appropriate surveillance interval has not yet been clearly established. To our knowledge, our multicenter nationwide randomized trial is the first study to compare different surveillance intervals in familial CRC. The participants were primarily selected by GPs and gastroenterologists from all parts of the Netherlands. The study population is therefore representative for all such individuals in the Netherlands. The intention-to-treat analysis showed that there was no statistically significant difference in the presence of AAPs at the first follow-up examination between individuals who had colonoscopy at 6 years compared with those who underwent colonoscopy at 3 years. However, if we corrected for the difference of AAPs at baseline, the difference became statistically significant.

There was also no statistically significant difference in the presence of AAPs at the final examination at 6 years between the individuals who had one follow-up examination 6 years after the baseline colonoscopy and those who had two follow-up examinations after 3 and 6 years. After correction for the difference in presence of AAPs at baseline, the difference became statistically significant.

Several cautionary notes must be made with regard to our findings. First, the fact that more participants in the 6-year group compared with the 3-year group underwent a colonoscopy that deviated from the original protocol may have influenced the outcome.

A clinically important finding was the observation of a relatively low absolute rate $(6.9 \%)$ of AAPs in group $\mathrm{A}$, in addition to the absence of CRC in this group. Although there was a significant difference in AAPs between the two groups, in view of this relatively low rate of AAPs and the absence of CRC in group A, we consider a 6-year surveillance interval appropriate for individuals with familial CRC. However, a 3-year surveillance interval might be recommended for patients with AAPs. Future studies in larger groups should compare 6and 10-year surveillance intervals.

A strength of this study is its randomized design. Moreover, family history was verified by medical reports in $99 \%$ of all patient cases and by pathology reports in almost $50 \%$ of patient cases. All adenomas identified at baseline and follow-up colonoscopies were revised by one pathologist.

A possible weakness of the study is that the colonoscopies were performed in various university and regional hospitals in the Netherlands. However, all colonoscopic examinations were performed by well-trained gastroenterologists, and appropriate cecal intubation rates were achieved. Moreover, additional imaging was performed if the colonoscopy was incomplete.

A second weakness of the study is that there were a few patient cases of early-onset CRC in which MSI or immunohistochemical analysis of the mismatch-repair proteins was not performed. These patient cases of CRC may have represented Lynch syndrome. However, because the detection rate of a pathogenic mismatch-repair mutation in patients with CRC before the age of 50 years is only $6 \%,{ }^{32}$ and the possible patient cases of Lynch syndrome were randomly distributed among the two arms of the study, we do not expect our findings to be significantly affected by inclusion of patients with incidental Lynch syndrome.

A third limitation of the study is that the statistical power was limited, and AAPs are a surrogate outcome to CRC and CRC-related mortality.

In summary, and taking all the findings of this study into consideration, a 6-year colonoscopic surveillance interval can be recommended in familial CRC. Future studies should address the upper age limit for surveillance and, in particular, determine the cutoff point at which the advantages of surveillance are outweighed by disadvantages of colonoscopic surveillance.

\section{AUTHORS' DISCLOSURES OF POTENTIAL CONFLICTS OF INTEREST}

Disclosures provided by the authors are available with this article at www.jco.org.

\section{AUTHOR CONTRIBUTIONS}

Conception and design: Andrea E. van der Meulen-de Jong, Jan H. Kleibeuker, Fokko M. Nagengast, Annemieke Cats, Hans F.A. Vasen Provision of study materials or patients: Stijn L.P. Crobach, Marco C.J.M. Becx, Wiet F.S.J. Crobach, Michiel van Haastert, Rogier ten Hove, Jan H. Kleibeuker, Maarten A.C. Meijssen, Fokko M. Nagengast, Marno C.M. Rijk, Jan M.J.I. Salemans, Arnold Stronkhorst, Hans A.R.E. Tuynman, Juda Vecht, Marie-Louise Verhulst, Wouter H. de Vos tot Nederveen Cappel, Herman Walinga, Olaf K. Weinhardt, Dik Westerveld, Anne M.C. Witte, Hugo J. Wolters, Annemieke Cats, Roeland A. Veenendaal, Hans Morreau, Hans F.A. Vasen

Collection and assembly of data: Simone D. Hennink, Andrea E. van der Meulen-de Jong

Data analysis and interpretation: Simone D. Hennink, Ron Wolterbeek, Hans F.A. Vasen

Manuscript writing: All authors

Final approval of manuscript: All authors

\section{REFERENCES}

1. Brenner $\mathrm{H}$, Kloor $\mathrm{M}$, Pox $\mathrm{CP}$ : Colorectal cancer. Lancet 383:1490-1502, 2014

2. Kapidzic A, Grobbee EJ, Hol L, et al: Attendance and yield over three rounds of populationbased fecal immunochemical test screening. Am J Gastroenterol 109:1257-1264, 2014

3. Parente F, Boemo C, Ardizzoia A, et al: Outcomes and cost evaluation of the first two rounds of a colorectal cancer screening program based on immunochemical fecal occult blood test in northern Italy. Endoscopy 45:27-34, 2013

4. Inadomi JM, Vijan S, Janz NK, et al: Adherence to colorectal cancer screening: A randomized clinical trial of competing strategies. Arch Intern Med 172:575-582, 2012

5. Khalid-de BC, Jonkers D, Smits K, Mesters I, et al: Participation in colorectal cancer screening trials after first-time invitation: A systematic review. Endoscopy 43:1059-1086, 2011

6. Leffler DA, Neeman N, Rabb JM, et al: An alerting system improves adherence to follow-up recommendations from colonoscopy examinations. Gastroenterology 140:1166-1173, 2011

7. Quintero E, Castells A, Bujanda $L$, et al: Colonoscopy versus fecal immunochemical testing in colorectal-cancer screening. N Engl J Med 366: 697-706, 2012

8. Stoop EM, de Haan MC, de Wijkerslooth TR, et al: Participation and yield of colonoscopy versus noncathartic CT colonography in population-based screening for colorectal cancer: A randomised controlled trial. Lancet Oncol 13:55-64, 2012

9. Hewitson P, Glasziou P, Irwig L, Towler B, Watson E. Screening for colorectal cancer using the faecal occult blood test, Hemoccult. Cochrane Database Syst Rev 24:CD001216, 2007

10. Faivre J, Dancourt V, Lejeune C, et al: Reduction in colorectal cancer mortality by fecal occult blood screening in a French controlled study. Gastroenterology 126:1674-1680, 2004

11. Brenner $H$, Stock $C$, Hoffmeister M: Effect of screening sigmoidoscopy and screening colonoscopy on colorectal cancer incidence and mortality: Systematic review and meta-analysis of randomised controlled trials and observational studies. BMJ 348:g2467, 2014

12. Jørgensen OD, Kronborg O, Fenger C: A randomised study of screening for colorectal cancer 
using faecal occult blood testing: Results after 13 years and seven biennial screening rounds. Gut 50:29-32, 2002

13. Johns LE, Houlston RS: A systematic review and meta-analysis of familial colorectal cancer risk. Am J Gastroenterol 96:2992-3003, 2001

14. Houlston RS: Colorectal cancer screening. Crit Rev Oncol Hematol 30:183-187, 1999

15. Butterworth AS, Higgins JP, Pharoah P: Relative and absolute risk of colorectal cancer for individuals with a family history: A meta-analysis. Eur $\mathrm{J}$ Cancer 42:216-227, 2006

16. Baglietto $L$, Jenkins $M A$, Severi $G$, et al: Measures of familial aggregation depend on definition of family history: Meta-analysis for colorectal cancer. J Clin Epidemiol 59:114-124, 2006

17. Ait Ouakrim D, Lockett $T$, Boussioutas A, et al: Screening participation for people at increased risk of colorectal cancer due to family history: A systematic review and meta-analysis. Fam Cancer 12:459472, 2013

18. Bleiker EM, Menko FH, Taal BG, et al: Screening behavior of individuals at high risk for colorectal cancer. Gastroenterology 128:280-287, 2005

19. Taylor DP, Cannon-Albright LA, Sweeney C, et al: Comparison of compliance for colorectal cancer screening and surveillance by colonoscopy based on risk. Genet Med 13:737-743, 2011
20. Mesher D, Dove-Edwin I, Sasieni $P$, et al: A pooled analysis of the outcome of prospective colonoscopic surveillance for familial colorectal cancer. Int J Cancer 134:939-947, 2014

21. Gaglia P, Atkin WS, Whitelaw $S$, et al: Variables associated with the risk of colorectal adenomas in asymptomatic patients with a family history of colorectal cancer. Gut 36:385-390, 1995

22. Hunt LM, Rooney PS, Hardcastle JD, et al: Endoscopic screening of relatives of patients with colorectal cancer. Gut 42:71-75, 1998

23. Lindgren $G$, Liljegren $A$, Jaramillo $E$, et al: Adenoma prevalence and cancer risk in familial non-polyposis colorectal cancer. Gut 50:228-234, 2002

24. Syrigos KN, Charalampopoulos A, Ho JL, et al: Colonoscopy in asymptomatic individuals with a family history of colorectal cancer. Ann Surg Oncol 9:439-443, 2002

25. Wark PA, Wu K, van't Veer $P$, et al: Family history of colorectal cancer: A determinant of advanced adenoma stage or adenoma multiplicity? Int J Cancer 125:413-420, 2009

26. Davila RE, Rajan E, Baron $T H$, et al: ASGE guideline: Colorectal cancer screening and surveillance. Gastrointest Endosc 63:546-557, 2006
27. Dunlop M, Campbell H: Screening for people with a family history of colorectal cancer. BMJ 314:1779-1780, 1997

28. Levin B, Lieberman DA, McFarland B, et al: Screening and surveillance for the early detection of colorectal cancer and adenomatous polyps, 2008: A joint guideline from the American Cancer Society, the US Multi-Society Task Force on Colorectal Cancer, and the American College of Radiology. Gastroenterology 134:1570-1595, 2008

29. van der Meulen-de Jong $A E$, Morreau $H$, Becx $M C$, et al: High detection rate of adenomas in familial colorectal cancer. Gut 60:73-76, 2011

30. de Jong AE, Vasen HF: The frequency of a positive family history for colorectal cancer: A population-based study in the Netherlands. Neth $J$ Med 64:367-370, 2006

31. Dove-Edwin I, Sasieni P, Adams J, et al: Prevention of colorectal cancer by colonoscopic surveillance in individuals with a family history of colorectal cancer: 16 year, prospective, follow-up study. BMJ 331:1047, 2005

32. Niessen RC, Berends MJ, Wu Y, et al: Identification of mismatch repair gene mutations in young patients with colorectal cancer and in patients with multiple tumours associated with hereditary nonpolyposis colorectal cancer. Gut 55:1781-1788, 2006

\section{Conquer Cancer Foundation of the American Society of Clinical Oncology}

The Conquer Cancer Foundation (CCF) was created by the world's foremost cancer physicians of the American Society of Clinical Oncology to seek dramatic advances in the prevention, treatment, and cures of all types of cancer. Working toward the vision of a world free from the fear of cancer, CCF strives to conquer this disease by funding breakthrough cancer research and sharing cutting-edge knowledge with patients and physicians worldwide, and by improving the quality of care and access to care, enhancing the lives of all who are touched by cancer. For more information, visit www.conquercancerfoundation.org. For information on The Campaign to Conquer Cancer, visit: conquer.org. 


\section{AUTHORS' DISCLOSURES OF POTENTIAL CONFLICTS OF INTEREST}

\section{Randomized Comparison of Surveillance Intervals in Familial Colorectal Cancer}

The following represents disclosure information provided by authors of this manuscript. All relationships are considered compensated. Relationships are self-held unless noted. I = Immediate Family Member, Inst = My Institution. Relationships may not relate to the subject matter of this manuscript. For more information about ASCO's conflict of interest policy, please refer to www.asco.org/rwc or jco.ascopubs.org/site/ifc.

Simone D. Hennink

No relationship to disclose

Andrea E. van der Meulen-de Jong

Honoraria: Tramedico

Consulting or Advisory Role: Abbott/AbbVie

Research Funding: Abbott/AbbVie (Inst)

Travel, Accommodations, Expenses: Abbott/AbbVie

Ron Wolterbeek

No relationship to disclose

A. Stijn L.P. Crobach

No relationship to disclose

Marco C.J.M. Becx

No relationship to disclose

Wiet F.S.J. Crobach

No relationship to disclose

Michiel van Haastert

No relationship to disclose

W. Rogier ten Hove

No relationship to disclose

Jan H. Kleibeuker

No relationship to disclose

Maarten A.C. Meijssen

No relationship to disclose

Fokko M. Nagengast

No relationship to disclose

Marno C.M. Rijk

No relationship to disclose

Jan M.J.I. Salemans

No relationship to disclose

\section{Arnold Stronkhorst}

No relationship to disclose

Hans A.R.E. Tuynman

No relationship to disclose

Juda Vecht

No relationship to disclose

Marie-Louise Verhulst

No relationship to disclose

Wouter H. de Vos tot Nederveen Cappel

No relationship to disclose

Herman Walinga

No relationship to disclose

Olaf K. Weinhardt

No relationship to disclose

Dik Westerveld

No relationship to disclose

Anne M.C. Witte

No relationship to disclose

Hugo J. Wolters

No relationship to disclose

Annemieke Cats

No relationship to disclose

Roeland A. Veenendaal

Travel, Accommodations, Expenses: Takeda Pharmaceutical (I), Ferring Pharmaceuticals

Hans Morreau

No relationship to disclose

Hans F.A. Vasen

No relationship to disclose 


\section{Acknowledgment}

We thank our study coordinators Nandy Hofland, Department of Clinical Genetics of the Leiden University Medical Center, and Mary Velthuizen, Department of Clinical Genetics of the University Medical Center Utrecht. We also thank Sanne van Erp for helping in the process of data management. 